\title{
19.1.
}

\section{Potencialidades da metodologia photovoice na intervenção com pessoas idosas institucionalizadas}

\author{
Rosalinda Chaves
}

\begin{abstract}
Resumo:
O envelhecimento tem sido assumido como vitória e desafio mundial, destacando-se como fenómeno contemporâneo de enorme pertinência. As instituições têm uma enorme responsabilidade na garantia do bem-estar e dignidade dos idosos, para que elas próprias não se tornem numa ameaça. É de enorme importância continuar a apostar-se num melhor entendimento dos fatores associados à realidade da institucionalização e continuar a fomentar a implementação de boas práticas neste género de cuidados, para que melhor se promova o bem-estar destas pessoas. Empregues em diversos campos do saber, as metodologias visuais têm vindo a afirmarse como vias credíveis e legítimas de exploração da realidade social e cultural, estando o recurso a tecnologias e a linguagens artísticas a ser cada vez mais utilizado, nomeadamente com idosos. O Photovoice, metodologia de fotografia participativa desenvolvida e ampliada por Wang e Burris (1997), é um processo através do qual as pessoas identificam, representam e impulsionam a sua comunidade. Este artigo almeja refletir sobre o Photovoice enquanto forma de intervenção e pesquisa pelo bem-estar de idosos institucionalizados. Englobará uma análise do conceito na velhice, integrandose a reflexão sobre a vantagem da utilização desta metodologia com tais populações.
\end{abstract}

Palavras-chave: photovoice; idosos; fotografia-participativa; bem-estar.

\begin{abstract}
:
Aging has been seen both as a victory and a global challenge, a contemporary phenomenon of great relevance. Institutions have a huge responsibility on assuring wellbeing and dignity, so that they themselves do not become a threat. It is extremely important to invest in a better understanding of the factors associated with institutionalization and continue to implement good practices, so that they best promote
\end{abstract}


the well-being of the elderly. Visual methodologies have been seen as a credible and legitimate way of exploring social and cultural reality, with technology and artistic languages increasingly used, especially with the elderly. Photovoice is a participatory photographic technique developed by Wang and Burris (1997), a process by which people can identify, represent and boost the community spirit. This article aims to offer a reflection about Photovoice as a method of intervention and research with the institutionalized elderly. It encompasses an analysis of the concept of well-being in old age, demonstrating the advantages of using this methodology with such populations.

Keywords: photovoice; elderly; participatory-photograpy; well-being.

\section{Introdução}

O mundo corre hoje a um ritmo nunca antes visto; a ciência trouxe muitas alterações e a vida como se entendia há um século em pouco se assemelha. No domínio da saúde, em particular, questionamos: vivemos hoje mais anos; mas sob que condições?

O envelhecimento da população tornou-se foco de preocupação mundial, oficializada pela Organização Mundial de Saúde (2002) desde finais dos anos 90, tanto pelos seus ganhos, como pelos seus desafios. Por todo o mundo, a proporção de pessoas com mais de 60 anos tem vindo a aumentar mais do que qualquer outra faixa etária. Viver mais anos representa uma vitória. "Viver mais tempo implica envelhecer. Maior longevidade não é um fatalismo ou uma ameaça. É uma vitória da humanidade e uma oportunidade de potenciar o património imaterial que significa o contributo das pessoas mais velhas" (Governo de Portugal, 2012: 3).

Investigações têm vindo a reforçar que o envelhecimento será uma experiência possivelmente bem mais positiva do que antes se acreditava (Fragoso, 2012; Lima, 2010; OMS, 2002; 2015; Rebelo, 2007; Ribeiro, 2012) e que o envolvimento contextualizado em atividades artísticas, per si, poderá potenciar oportunidades de sociabilização, produzindo diferentes desafios e criando-se condições para o aparecimento de novos interesses e para a manutenção de sentimentos de pertença e de participação na comunidade (Milhano, 2014), desenvolvendo inúmeras competências (Flood \& Phillips, 2007; Woodhouse, 2013), processos meta-cognitivos de extrema pertinência (Formosa, 2013).

No entanto, é frequente que investigadores se coloquem em posição de "agir por" ou "em nome de" pessoas e comunidades, cujas vozes foram naturalmente silenciadas, acabando por evitar que elas sejam ouvidas, completamente compreendidas ou apreciadas. Empregues em diversos campos do saber, as metodologias visuais têm 
vindo a afirmar-se como vias credíveis e legítimas de exploração da realidade social e cultural (Campos, 2011), estando o recurso a tecnologias e a linguagens artísticas a ser cada vez mais utilizado, nomeadamente com idosos.

Por sua vez, a fotografia "representa uma troca do homem consigo mesmo, uma forma de ver e de ser visto" (Bulla Júnior, 2005: 217). Representação imagética do mundo, a fotografia é espelho, transformação e discurso do real (Dubois, 1993), "certificado de presença" (Barthes, 1981: 122). A ligação emocional e comunicacional à imagem está presente na evolução humana desde tempos remotos (Campos, 2013), mas hoje é possível ao mais comum dos mortais usá-la para comunicar, independentemente do seu estatuto, 'raça', idade ou género, por gosto e por prazer, pelo lúdico, pelo estado de alma que reflete, enfim, por algo que está inerente ao ser: a partilha do que é nosso.

O Photovoice, método desenvolvido e ampliado por Caroline Wang e Mary Ann Burris (1997) é um processo através do qual as pessoas identificam, representam e impulsionam a sua comunidade através da fotografia, expressando o seu olhar interno. Este artigo almeja refletir sobre o Photovoice enquanto forma efetiva de intervenção e pesquisa pelo bem-estar de pessoas mais velhas, em particular, aquelas institucionalizadas em Estruturas Residenciais. Segue-se uma introdução teórica que explana o tema do envelhecimento populacional, contextualizando-o no domínio português. Englobará uma análise geral do conceito de bem-estar na velhice, integrando-se aqui a possível vantagem da utilização desta metodologia com tais populações.

\section{Envelhecimento em Portugal}

O aumento da longevidade trouxe claros riscos para a manutenção do bem-estar da humanidade (Barreto, 2005). Assim, o envelhecimento tem vindo a ser assumido como uma vitória mas também enquanto problema mundial (OMS, 2002), destacando-se enquanto fenómeno contemporâneo de enorme pertinência e preocupação (Antunes \& Pereira, 2014; Barros de Oliveira, 2010; Capucha, 2014; Carvalho, 2014; Fonseca, 2004; Jacob, 2012; Sequeira, 2010; Tomé et al., 2015).

A velhice tornou-se tema comum da atualidade, foco recorrente de atenção e, até mesmo, alvo de investimento por parte dos mais diversos domínios. O envelhecimento deixou de ser uma realidade escondida (Carvalho, 2014), assumindo-se como mais do que uma necessidade de foco assistencialista, uma questão social, política e de defesa dos direitos humanos. Ao mesmo tempo, a velhice tornou-se igualmente banal (Barreto, 2005), já não tão respeitada e admirada como antes.

Supostamente protegida, a velhice nem sempre é encarada de forma positiva, apesar de Cohen (2006) defender que a partir de 1975 se terá dado uma mudança na forma 
como se perspetiva o envelhecimento, ao se perceber que determinadas perdas decorrerão, maioritariamente, de problemas específicos, e não do decorrer dos anos em si, passando a se assumir um sentido de responsabilidade diferente sobre a maneira como se pode atuar sobre tais questões. Etapa cada vez mais longa e significativa, assume-se urgente pesquisar os fatores que podem intensificar um envelhecer ativo e saudável (Esgalhado et al., 2014), digno e respeitador da pessoa, no seu potencial como um todo.

Vivemos no desejo de não ficarmos velhos (Sequeira, 2010), mas envelhecemos desde que nascemos; o envelhecimento é parte indissociável da vida. Não obstante esta realidade, a verdade é que a velhice continua a assumir uma conotação negativa, pessimista e bastante limitativa (Formosa, 2013; Miguel, 2014). As pessoas idosas são identificadas pela sua idade e pelo direito a prestações financeiras (pensões) como contrapartida da perda do estatuto de sujeitos ativos (Cardoso, Santos, Baptista \& Clemente, 2012). Tais conceções afetam não só os comportamentos das gerações mais novas, como influenciam igualmente a visão que as próprias pessoas mais velhas têm sobre o envelhecimento e sobre a sua própria forma de estar. Mas citando Barros de Oliveira (2010: 11), “(...) é secundário o modo como apelidamos os velhos e a velhice. Mais importante é compreendê-los e ajudá-los":

Em Portugal, o número de pessoas idosas tem aumentado substancialmente (Instituto Nacional de Estatística, 2011; 2014), gerando altos desafios tanto no domínio da segurança social, sistema de saúde e pensões, como no que diz respeito à qualidade dos cuidados. O Estado Social assume-se inevitavelmente como garantidor do bemestar dos idosos, especialmente daqueles desprotegidos e desenquadrados da sua estrutura familiar. Situação acrescida pela atual crise económica mundial, a atenção à população idosa tem exigido maiores cuidados, não só aqueles que naturalmente surgiriam, mas também pelo empobrecimento geral da população, refletido numa faixa etária com crescentes dificuldades de acesso a serviços limitados e a apoios.

No nosso país, esta situação económica exponenciou, ainda mais, movimentos migratórios, potenciando que muitas pessoas mais novas procurem alternativas nas grandes cidades ou noutros países e, por conseguinte, reduzam automaticamente o apoio que prestavam, por proximidade, aos seus pais ou avós. A fragilização gradual das famílias tradicionais e das redes próximas de suporte social, importante elemento de bem-estar (Barreto, 2005; Paúl, 2005), têm-se evidenciado como mais um fator gerador de dificuldades ao bom perspetivar desta fase da vida, já para não falar da probabilidade acrescida de casos de negligência e maus tratos.

Prioridade inquestionável, não só se têm exigido alterações económico-políticas como as próprias estruturas dedicadas ao apoio à população idosa, também elas, têm vindo 
a adaptar-se a esta realidade. Jacob (2012) refere a existência de dois tipos de apoios em Portugal destinados à pessoa idosa: os financeiros e as infraestruturas e serviços, dos quais fazem parte as unidades de saúde e os equipamentos sociais. Dentro dos equipamentos, as respostas são as organizações locais de apoio à população idosa, nomeadamente através de Universidades Sénior, Centros de Dia, Centros de Convívio, Centros de Noite, Serviços de Apoio Domiciliário (SAD), Residências Assistidas, Estruturas Residenciais para Pessoas Idosas (ERPI) e Residências Sénior, entre outros. Algumas das instituições que promovem este género de cuidados assumem para si, localmente, parte das responsabilidades e deveres do Estado (Carvalho, 2014), através do estabelecimento de protocolos oficiais com o Governo e Segurança Social: as Instituições Particulares de Solidariedade Social (IPSS's). Outras organizações com ou sem fins lucrativos têm gradualmente surgido, não tendo, no entanto, protocolo oficial. Não sendo preferência primordial das pessoas (Fericgla, 1992 citado por Osorio, 2008), as estruturas residenciais têm representado uma opção cada vez mais frequente. Sobre elas, Barreto (1998: 18) elaborava no panorama nacional uma conjetura que parece permanecer atual. Segundo este autor, existem dois tipos de lares: os lucrativos ("na sua maioria clandestinos" ou a atuar acima da lotação aprovada) e os não lucrativos (geralmente IPSS's, de "ambiente físico e humano geralmente mais favorável"). Apesar das profundas transformações em Portugal relativas à passagem dos antigos asilos e hospícios para aqueles que acolhem hoje os idosos de forma permanente, os lares continuam a acarretar em si uma carga simbólica muito forte e marcadamente negativa (Guedes, 2012), habitualmente temidos (Neto \& Corte-Real, 2013) e raramente encarados como projeto de vida (Jacob, 2012). Na verdade, nunca foi possível escutar nenhum idoso a expressar vivamente a sua profunda alegria e contentamento por viver num lar, mesmo quando as anteriores condições de vida eram bastante penosas (Guedes, 2012: 18).

A entrada num lar implica, pois, a reelaboração da forma como a pessoa encara a sua vida, devendo esse processo ser suportado da melhor forma possível. A adaptação à institucionalização é habitualmente difícil, e afeta em grande medida a sensação de bem-estar (Carvalho \& Dias, 2011; Paúl, 1997). O processo de entrada permanente numa instituição deste caráter representa sempre uma perda de autonomia e da vida anterior e interage, inevitavelmente, com a manutenção da identidade do idoso (Guedes, 2012).

As Instituições assumem, por isso, uma enorme responsabilidade na garantia do bemestar e dignidade de todos, por forma a certificar que o próprio lar não se torne numa ameaça à pessoa idosa. Possibilitar que as estruturas identitárias da pessoa se 
mantenham dignas e se adaptem e integrem na nova realidade, mais do que um dever, é uma urgência a se considerar diariamente.

\subsection{Envelhecimento Ativo: linhas orientadoras de intervenção}

Mais idade não é sinónimo de doença (Osorio, 2008), mas perdas significativas e alterações físicas acontecem com o avançar da idade cronológica (Lamas \& Paúl, 2013). O conceito de envelhecimento tem sofrido significativas alterações ao longo dos tempos (Sequeira, 2010), sendo determinado em boa parte por crenças, culturas, religiões, conhecimentos, e, portanto, não é estanque mas sim algo que continuará, bem possivelmente, a sofrer alterações no futuro.

No contexto do aumento dos desafios que uma maior longevidade acarreta, o paradigma de atuação (pelo menos o Europeu) tem vindo a mudar. O abandono de uma visão assistencialista e centrada na colmatação das necessidades básicas da pessoa enquanto agente social passivo tem vindo a generalizar-se, favorecendo-se a manutenção de uma vida com sentido e qualidade (Antunes \& Pereira, 2014). Assumese uma visão diferente, respeitadora do indivíduo enquanto ser ativo e capaz, protagonista do seu próprio desenvolvimento.

Quanto à intervenção, ela deve ter em conta diversos âmbitos complementares. As linhas de orientação propostas pela OMS $(2001$; 2002) recomendam generalizadamente o paradigma do "envelhecimento ativo". Tendo-se tornado indiscutível objetivo político (Ribeiro, 2012), a sua definição assenta num processo de otimização de oportunidades pela saúde, pela participação e pela segurança, por forma a se conseguir aumentar a qualidade de vida de cada pessoa conforme ela vai envelhecendo.

O envelhecimento ativo pressupõe realmente uma postura ativa da parte do indivíduo, pela realização do seu potencial e pela promoção do seu próprio bem-estar, onde a chave do sucesso passará pela manutenção da autonomia e da independência, não se distanciando do contexto das relações com os outros e da solidariedade intergeracional (OMS, 2002). Assim sendo, promove-se uma abordagem multidimensional, implicadora de responsabilização e participação de todos (inclusive do próprio) no combate à exclusão social e à descriminação, bem como pela promoção da igualdade e da solidariedade, por uma efetiva sociedade inclusiva (Carvalho, 2014; Governo de Portugal, 2012; Pereira, 2012).

O ritmo de envelhecimento varia de indivíduo para indivíduo, bem como varia a idade em que se inicia a fase de senescência ${ }^{1}$ (Barreto, 2005). Numa perspetiva de envelhecimento ao longo da vida (OMS, 2002), reconhece-se que as pessoas não são homogéneas, proclamando-se que as intervenções assentes na criação de ambientes de suporte saudáveis são da maior importância em todas as fases da vida. $O$ 
envelhecimento ativo representará, então, a continuação de uma vida ativa e inclusiva, vivida de forma participativa e tendo em conta o reconhecimento das possibilidades, expectativas e desejos pessoais de cada um (Gama, Teodoro \& Simões, 2014; Pereira, 2012). Procura-se o aumento da esperança de vida saudável, bem como a melhoria da qualidade de vida (Jacob, 2007). Um novo documento da OMS (2015) passa a usar o termo "envelhecimento saudável" como conceito talvez mais globalizante daquilo que se procura que seja este processo.

Mas o estereótipo de que as pessoas idosas são demasiado velhas para aprender ainda representa um enorme obstáculo a esta perspetiva de aprendizagem (Moody, 2002). A intervenção com pessoas de idade avançada tem, como tal, ganho evidente proeminência, baseada numa crença de que tanto os adultos mais novos como os mais velhos mantêm a capacidade de crescimento e mudança (Lima, 2004), sendo a posição contrária a este credo considerada discriminação - idadismo ${ }^{2}$.

Poder envelhecer com dignidade será o objetivo último, especialmente quando o envelhecimento surge associado à dependência, pelo que é crucial que se criem condições para que seja garantida a dignidade da pessoa alvo dos cuidados (Sequeira, 2010). Nesta perspetiva de investimento no processo de envelhecimento, o conceito de empowerment tem ganho terreno, a par do que tem vindo a acontecer noutras áreas de intervenção. Associado a uma melhor saúde (Wallerstein \& Bernstein, 1988), trata-se de um modelo que sugere igualmente a participação dos indivíduos na construção da própria mudança como promotora de uma maior efetividade e proximidade ao real, onde o recurso ao desenvolvimento de processos criativos parece deter uma importante vantagem (Formosa, 2013).

"Quando nos sentimos vítimas, encerramos a nossa capacidade de comunicar" (Lima, 2010: 125). Procura-se, pois, nos dias de hoje, encarar o envelhecimento como um processo positivo, numa perspetiva inclusiva, humanista e contextualmente sensível, prezando-se não tanto a quantidade mas a qualidade, isto é, "envelhecer bem". Falamos da forma como escolhemos escolher e decidir sobre a nossa vida.

Por sua vez, as soluções digitais têm ditado a modernidade, obrigando as pessoas, independentemente da sua idade ou vontade, a se adaptarem a esta nova realidade. Ultimamente, as tecnologias têm-se revelado vantajosas ferramentas de empowerment (Romero, Hyvönen \& Barberà, 2012), levantando-se, também por isso, a proeminência do seu uso com estas populações.

\subsection{Bem-Estar, Qualidade de Vida e Emoções na Velhice}

A promoção da saúde e do bem-estar tem vindo a ser cada vez mais encarada de uma forma global, implicando todas as dimensões da vida humana. Queremos viver mais 
anos, mas queremos poder usufruir capazmente dos mesmos. Mas os fatores que influenciam o bem-estar são imensos (Lima, 2010). Assim sendo, assume-se uma postura não só de atuação no problema como, também, preventiva e promocional. No que toca ao envelhecimento, assume-se como pertinente preparar no hoje "a velhice que se quer ter amanhã" (Governo de Portugal, 2012: 6). Infelizmente, se este aumento no tempo de vida tem acompanhado aumentos ao nível da qualidade de vida destas mesmas pessoas não tem sido claro (OMS, 2015).

$\mathrm{Na}$ velhice espera-se uma fase de balanço da vida, de experimentação de sentimentos de realização e/ou fracasso, de aceitação de si próprio e, em limite, do fim que se avizinha (Barreto, 2005), sendo isto flexível, nada universal e em muito relativo ao significado que se atribui às experiências de vida. Amplamente associado ao conceito de envelhecimento ativo surgem então, as noções de satisfação com a vida e qualidade de vida (Barros de Oliveira, 2010; Ribeiro, 2012), as quais não se dissociam de bemestar nem da forma como se vivenciam as emoções.

O bem-estar tem suscitado muita atenção nas últimas décadas (Barros de Oliveira, 2010; Galinha \& Pais-Ribeiro, 2005; Novo, 2005). Os primeiros estudos surgiram associados ao domínio económico (Pais-Ribeiro, 2009) e referiam-se a um conceito de Bem-Estar numa perspetiva mais material, distinguindo-se esta ideia daquilo que se considera ser hoje o Bem-Estar Global. A Saúde, nomeadamente a Saúde Mental, é considerada parte integrante do Bem-Estar Global, que, com o modelo Biopsicossocial ${ }^{3}$, passou a preocupar-se mais com aspetos positivos, descentralizando-se da doença.

Dentro do Bem-Estar Global, o Bem-Estar Subjetivo (BES) (Galinha \& Pais-Ribeiro, 2005) assume-se como noção chave de um campo de investigação emergente, a Psicologia Positiva. O conceito é organizado por uma dimensão cognitiva, denominada Satisfação com a Vida, e uma dimensão afetiva, a Felicidade. Já o Bem-Estar Psicológico (BEP) (Ryff, 1989), ligado à eudaimonia ${ }^{4}$, inclui na sua definição multidimensional: autoaceitação, relações positivas com outros, autonomia, domínio sobre o ambiente, propósito na vida e crescimento pessoal. Relaciona-se com o desenvolvimento pessoal, sendo que a investigação sobre estes conceitos se tem desenvolvido em articulação e em paralelo (Galinha \& Pais-Ribeiro, 2005; Machado \& Bandeira, 2012; Novo, 2005). Lawton (1983, citado por Paúl, 1992 citado por Esgalhado et al., 2014) associa o BEP a uma sensação geral de satisfação com a vida e com uma saúde mental positiva, relacionada com o estado interno da pessoa nas suas vertentes cognitivas e afetivas.

O bem-estar pressupõe um aspeto de enorme importância, a Qualidade de Vida (QdV). Poderá ser definido como a perceção de um indivíduo sobre a sua posição na vida no contexto cultural e de valores onde se insere, na sua relação com os seus objetivos, 
expetativas, padrões e preocupações, incorporando a sua saúde física, estado mental, nível de independência, relações sociais, crenças pessoais e relação com o ambiente (OMS, 2002). Num conceito que vai para além da ausência de doença (Pais-Ribeiro, 1994), a sua avaliação depende substancialmente da opinião do indivíduo (Silva, 2009). A avaliação destes construtos não é um assunto pacífico (Fonseca, 2004). Como defende Paúl (1997), numa análise global é inconcebível não atender às características individuais da pessoa idosa, só percetíveis no entendimento do seu curso de vida e na adaptação à sua realidade atual. Posto isto, é impensável dissociar o bem-estar das emoções, sentimentos e afetos, conceitos ainda que distintos, interatuam e relacionamse entre si.

As emoções mostram na forma como o nosso corpo reage, no domínio físico (respiração, tónus muscular, movimentos, expressão facial...), o que se passa na nossa mente. Podendo ser consideradas como agradáveis ou desagradáveis, as emoções são vividas no corpo, e são reflexo das vivências internas e estímulos externos a que a pessoa está sujeita (Fragoso, 2012).

António Damásio (2003) defende existirem emoções básicas, de origem inata, emoções secundárias ou sociais e emoções de fundo, onde se insere a sensação de bem-estar. Quando tais sensações se prolongam no tempo, tornam-se estados de humor (Fragoso, 2012), podendo, com o aumento da sua incidência e invalidação, vir a incorrer em diagnóstico de perturbação mental. Por sua vez, os sentimentos, mais privados e duradouros, serão processos mentais relativamente estáveis e acontecerão em resultado das emoções (Damásio, 2003). Refere Moura (2008, citado por Fragoso, 2012: 67) que "as emoções desenrolam-se no teatro do corpo; os sentimentos no teatro da mente".

Apesar de muitas pessoas decifrarem as emoções dicotomicamente, todas elas são importantes e úteis, funcionando como bússolas internas que podem potenciar o desenvolvimento e o crescimento pessoal (Fragoso, 2012). Muitas vezes mal conotadas, as emoções que geram sensações desagradáveis tentam ser controladas e, não raramente, dissimuladas ou, até mesmo, é negada a sua presença. Tal pode gerar o desenvolvimento de reatividades fisiológicas/psicossomáticas que, necessariamente, afetam o bem-estar da pessoa de tal forma que a situação se torna invalidante. Há, por isso, uma urgência antiga pela educação da faculdade de sentir (Rodrigues, 2011).

A emoção dá vida, dá movimento, é parte constituinte do nosso ser. Compreender as emoções da pessoa torna-se imperativo, e permitir que ela se compreenda a si própria é, portanto, imprescindível a uma efetiva intervenção pela promoção do bem-estar. Assim sendo, nesta utilização de metodologias visuais como forma de intervenção, é igualmente essencial atender à importância das mesmas e da potenciação de espaços 
para a sua ventilação, para que melhor se possa compreender a pessoa, e para que efetivamente se possa entender o que, para cada um, significa "bem-estar".

\section{Fotografia e Photovoice}

A lente fotográfica tem a capacidade de captar detalhes que escapam ao olho humano (Scharf, 1994). Por outro lado, a imagem está em tudo o que nos rodeia: "Vemo-la por toda a parte, sem aliás olharmos verdadeiramente para ela (...)" (Bauret, 2000: 9). Mecanismo dominante da comunicação contemporânea, com a imagem falamos de forma breve, sem bloqueios, sem grandes inquietações sobre o queremos transmitir. Assim, a fotografia representa, potencialmente, uma das melhores formas de expressão e libertação daquilo que há de mais interno em nós. Em Milagre dos homens, Rômulo de Carvalho postula (1976) a descoberta da fotografia como uma das realizações mais extraordinárias que os seres humanos conseguiram.

Reprodução da realidade, a fotografia veio revolucionar a imagem, inicialmente de forma até inconsciente das suas verdadeiras potencialidades. É incontestável como a fotografia se afirmou enquanto forma de expressão, de informação e de comunicação. Desde Daguerre e Talbot, a fotografia foi evoluindo de tal forma que hoje não só é fácil o seu processo de fixação, como ela deixou de existir apenas no domínio material, para se tornar recorrente o seu uso em suporte digital (Bauret, 2000). De facto, o aparecimento da fotografia e, mais tarde, do cinema, acarretou imensas alterações na história da humanidade, assumindo agora propósitos ficcionais, estéticos, documentais, narrativos e científicos (Campos, 2011).

"O homem é um ser eminentemente visual" (Rodrigues, 2011: 23). Dentro das imensas linguagens artísticas disponíveis, a fotografia representa, portanto, uma fonte inigualável de informação. Com ela podemos exprimir os nossos sentimentos, os nossos ideais, as nossas preocupações, conseguimos dizer mais do que aquilo que as palavras conseguem. Se a fotografia antes estava mais relacionada com a captação da realidade, hoje assume-se igualmente a sua função de construção do real. Espelho do mundo contemporâneo (Souza \& Lopes, 2002), forma de catalogar, revelar e redescobrir o mundo (Vega, 2004), a fotografia não é uma produção de imagens inocente, casual ou mecânica; trata-se de uma linguagem mais ou menos estruturada, não obstante as múltiplas abordagens que a consideram.

A fotografia é, por essência, testemunho artístico e jornalístico, prática social amplamente popular, a todos muito mais acessível, acompanhando o Ser Humano nas suas deslocações e atividades. Ela tem uma "maneira, só dela, de fazer parar o tempo" (Bauret, 2000: 114) possibilitando a transmissão de emoções de uma forma especialmente única. Com ela, "eternizamos o que é passageiro, tornamos a ver o que 
já passou, continuamos vivos depois de mortos" (Carvalho, 1976: 5), pois "ela repete mecanicamente o que nunca mais poderá repetir-se existencialmente" (Barthes, 1981: 17), tornando-se arquivo da memória (Vega, 2004), carregada, não raras vezes, de significado simbólico (Martin, 1987).

Posser (1998) defende um maior consenso no que toca à imagem poder ser encarada como forma de investigação. Numa era de revolução digital, alguns autores refletem sobre a importância da educação estética do olhar enquanto potenciadora da interação crítica e reflexiva, através das imagens do quotidiano, como combate à aquisição de conhecimentos banais e superficiais (Kowalski, 2013; Rodrigues, 2011; Souza \& Lopes, 2002). A fotografia pode oferecer caminhos para a elaboração de projetos inovadores, contribuindo com meios, espaços e estratégias que promovem o desenvolvimento de competências socio emocionais e comunicativas (Crespo \& Pulido, 2014; Cronin, 1998). Tirar uma fotografia consiste em capturar um momento e o que ele revela para mais tarde o comunicar. É representação do passado e presente, mas é igualmente portadora de um significado futuro (Kowalski, 2013). É muito mais do que ali se aprecia: implica uma história, um antes e um depois, um contexto e um significado. Envolve sentimentos e emoções, pensamentos mais ou menos conscientes, de quem a tira e de quem a vê. A imagem pode ser, por isso mesmo, fonte de pesquisa (Campos, 2011). Ao facilitar a recolha, análise e divulgação de tais dados, torna-se inegável a sua importância como forma de intervenção direta com pessoas e comunidades. A fotografia participativa é um método usado no desenvolvimento comunitário, saúde pública e educação, que concretiza a fotografia como base da ação social (Crespo \& Pulido, 2014). Não raramente, é utilizada por múltiplos atores e contextos, dentro de âmbitos de atuação mais ou menos estruturados. Photovoice, autobiografia e fotografia comunitária são técnicas de fotografia participativa usadas para dar voz e reativar o poder das pessoas e comunidades em busca da mudança social (Griebling et al., 2013).

Existem realmente diferentes modos de utilizar a imagem interventivamente, como, por exemplo, photo-elicitation (Harper, 2002) e participatory-video (Harrison, 2002), mas o Photovoice é o procedimento mais consolidado em termos metodológicos. Wang e Burris (1997) são as autoras reconhecidas pela implantação, desenvolvimento e divulgação do Photovoice, uma metodologia fotográfica participativa que permite às pessoas identificarem, representarem e impulsionarem a sua comunidade, baseada na produção de conhecimento. O conceito foi desenvolvido através de três diferentes fontes: da literatura teórica e educacional sobre consciência crítica, teoria feminista e abordagens não tradicionais de fotografia documental; do trabalho de fotógrafos e educadores comunitários como desafiadores da representatividade dos documentários; e da sua própria experiência na aplicação do processo ${ }^{5}$. Desde aí, esta metodologia 
tem-se tornado conhecida e utilizada nos mais variados contextos (Catalini \& Minkler, 2010).

Forma de investigação-ação colaborativa, implica um processo em que máquinas fotográficas são entregues a pessoas para que possam funcionar como "gravadores» das suas comunidades sem grandes exigências técnicas, assumindo assim o potencial de poderem ser catalisadoras de mudança (PhotoVoice.org, s.d.; Wang \& Burris, 1997). Ao atuarem pelo interesse de si mesmos e não do investigador, permite-se a avaliação de necessidades, pela oportunidade de documentarem a sua própria realidade. Esperase assim atingir uma autenticidade que de outra forma não seria possível se fotografada por quem vê, mas não o vive (Kowalski, 2013).

Adaptado da educação para a saúde de Wallerstein e Bernstein (1988) e baseado nos princípios propostos sobre consciência crítica e emancipadora de Paulo Freire (1979; 2005) sobre a imagem como meio de potenciação do pensamento crítico, parte daquilo que as pessoas consideram como central nas suas vidas e que identificam como temas comuns. Sendo inspirado mas diferente da fotografia documental e jornalística, trata-se de uma metodologia que oferece a oportunidade de fotografar a pessoas que dificilmente teriam acesso a tal ferramenta de forma consciente, transformando-as em sujeitos ativos, diretores das suas próprias intenções e representações. É neste sentido que se trata de uma forma de investigação participativa mas, igualmente, de intervenção pela mudança. Efetivamente,

A aquisição de conhecimento por si só não chega, mantém a ignorância, porque a assimilação de factos sem um contexto e sem uma intenção poderão promover a aquisição de informação, mas não sendo esta processada através de uma análise crítica, torna-se demasiado superficial para construir um conhecimento sobre algo. (Kowalski, 2013: 9)

Não existirá conhecimento nem criatividade sem que haja reflexão. Existem, portanto, alguns conceitos que envolvem transversalmente esta técnica. A imagem ensina (Wang, 1999), molda os nossos ideais e a forma como nos vemos a nós mesmos e ao mundo. Talvez por isso mesmo, a imagem exerce influência no mundo político, podendo alterálo, e é usada por este fornecendo indicações sobre o que deverão ser os interesses públicos. Ao potenciarmos que os indivíduos usem crítica e conscientemente a imagem, poderá ser possível intervir politicamente e, por isso, as perspetivas fotografadas têm que chegar a pessoas socialmente influentes, enfatizando-se a ação individual e comunitária.

Dependendo do grupo alvo, existirão diferentes objetivos e resultados na partilha das descobertas decorrentes de um projeto de Photovoice (Palibroda et al., 2009), nomeadamente, o desafiar de estereótipos negativos e a captura de atenção e suporte por parte dos policy-makers, por uma maior consciencialização sobre os problemas de 
determinada comunidade, visando alterações de leis e políticas. Em diferentes contextos e com os mais variados públicos, Wang e Burris (1997) postulam que o Photovoice adota declaradamente três objetivos transversais: permitir às pessoas gravar e refletir as potencialidades e preocupações da sua comunidade; promover o diálogo crítico e o conhecimento sobre assuntos importantes da comunidade, através do debate em grupo sobre as fotografias e; chegar aos autarcas, políticos e figuras de importância social.

Procura-se fazer com que vozes sejam ouvidas e encorajar o autodesenvolvimento (PhotoVoice.org, s.d.). Trata-se de uma metodologia que acaba por motivar uma colaboração mais estruturada entre investigador e participantes, ao mesmo tempo que desenvolve competências pessoais e coletivas (Meirinho, 2015). Em termos sociopolíticos, a envolvência daqueles com poder de decisão permitirá uma operacionalização mais efetiva e próxima das pessoas, para quem o Estado Social é suposto existir.

É através da sensibilidade do olhar que a sensibilidade do espírito se exprime (Bauret, 2000). A fotografia é uma ferramenta apelativa, fácil de usar, próxima do ser humano. Assim sendo, múltiplos projetos têm vindo a ser desenvolvidos um pouco por todo o globo e são representativos da utilização do Photovoice para trabalhar questões de ordem social complexas. Recorrendo à experiência e perceção dos participantes, promove-se a criatividade e a autonomia. Em quase todos os casos os participantes ganharão autoestima (PhotoVoice.org, s.d.). Promove-se a investigação, mas também a participação e a ação de grupos e comunidades, num verdadeiro envolvimento das pessoas em refletirem sobre si mesmas pelo autocrescimento.

Em Portugal, projetos no domínio do uso da imagem como forma de intervenção têm sido desenvolvidos, investigados e divulgados. O W2P (Caballero et al., 2013) é inspirado no Projeto SenseCam, que usa uma câmara minúscula para gravar as atividades do quotidiano. Neste programa, as pessoas realizavam uma rota fotográfica pela cidade, estimulando-se, primariamente, a memória. Daniel Meirinho (2012; 2015) tem desenvolvido um importante contributo, havendo investigado e divulgado o projeto Olhares em Foco, onde a fotografia participativa tornou-se elemento de representação e reflexão identitária de jovens provenientes de meios desfavorecidos, no Brasil e em Portugal. Em Leiria, a InPulsar ${ }^{6}$, tem feito trabalhos vanguardistas usando o Photovoice pela comunidade. O Projeto REALidades, em Coimbra, usa o Photovoice como forma de intervenção com pessoas idosas ${ }^{7}$. Uma iniciativa intergeracional, que visa fomentar o contacto e a proximidade entre universitários da cidade e idosos residentes na Alta de Coimbra. Em Lisboa, a FOS, uma associação sócio-cultural que utiliza metodologias 
participativas no campo da imagem, desenvolve-se o FOS - Olho Aberto Olhar Desperto, como potenciador da inclusão social e digital.

A imagem generalizou-se e, quotidianamente, somos levados a usá-la, decifrá-la e interpretá-la. Não obstante o automatismo do mundo digital contemporâneo, a imagem fotográfica é mais que um produto da máquina; ela reflete uma escolha significativa do fotógrafo, que influencia determinantemente o seu resultado. Implementar a fotografia participativa é dar oportunidade a que se escutem pontos de vista, vozes, lutas, valorizando o que verdadeiramente se pensa e o que realmente se sente.

\section{Potencialidades da utilização do Photovoice com pessoas idosas}

Lima (2010) resume os principais desafios do envelhecimento como sendo o reconhecimento da inevitabilidade da mudança, da imprevisibilidade da vida e o confronto com a morte. É pois um dos maiores estímulos da sociedade contemporânea o desenvolver de projetos para as pessoas mais velhas que possam potenciar o encontro de novos significados, fortalecendo atitudes de decisão e autonomia (Myers, 1993 citado por Milhano, 2012), nomeadamente através de ferramentas criativas, tornando-as protagonistas do seu próprio desenvolvimento.

A arte é libertadora de emoções, intermediária na comunicação e no crescimento do indivíduo, assumindo um potencial inclusivo (Oliveira, 2007), estando frequentemente ligada ao desenvolvimento da criatividade e ao ato criador. Rogers (1974: 301) define o processo criador como "uma emergência na acção de um novo produto relacional", natureza única da pessoa, na sua interação com materiais, acontecimentos e pessoas. A criatividade é, portanto, considerada parte do Ser, e faz parte das necessidades da pessoa a sua realização (Ostrower, 1993), evidenciando-se como uma competência chave para a prosperidade pessoal e social. Assim sendo, a estimulação da criatividade é encarada como uma mais-valia pela promoção do bem-estar, nos mais diversos contextos, independentemente de grupos e idades.

A criatividade surge associada à adaptabilidade, à autoexpressão e à saúde (Runco, 2004). Em pessoas mais velhas, autores associam-na ao bem-estar (e.g. Flood \& Phillips, 2007; Woodhouse; 2013), evidenciando como o envolvimento em atividades criativas parece melhorar diversas habilidades, nomeadamente, no domínio da resolução de problemas, autoestima, competências de coping, ansiedade, locus de controlo interno, satisfação com a vida, sintomas depressivos e hipocondria. Potencia o desenvolvimento de mecanismos de autocontrolo, de influência da mente sobre o corpo, de envolvimento social e de plasticidade cerebral (Cohen, 2006). Aptidão que pode ser dinamicamente aprendida e desenvolvida ao longo da vida, a maioria das pessoas de 
idade avançada não se considera, no entanto, criativa (Flood \& Phillips, 2007), revelando-se relutante a atividades de tal ordem.

Resposta efetiva à evolução (Runco, 2004), o ato criador envolve variados processos abrangendo, portanto, a capacidade de compreender, bem como a de relacionar, ordenar, configurar e significar (Ostrower, 1993). As artes e a participação criativa têmse revelado fundamentais para manter as pessoas idosas envolvidas (Woodhouse, 2013) de formas não antes imagináveis (Moody, 2002). Vão sendo cada vez mais os projetos alicerçados no recurso às artes com idosos, difundindo-se por todo o mundo os resultados que colocam a tónica na inclusão e no envolvimento ativo, pela melhoria do seu Bem-Estar Global (Milhano, 2012), acompanhando simultaneamente estas intervenções a evolução tecnológica (Roberto, Fidalgo \& Buckingham, 2014).

A atividade recreativa é necessária ao ser humano, especialmente em altura de privação ou cessação de ocupações, podendo ajudar a reparar sentimentos de perda, promovendo o reencontro do sujeito consigo mesmo (Hilário, 2007). Tendo em conta toda a contextualização teórica até aqui mencionada, são conhecidas as imensas potencialidades de se utilizar a arte não como produção estética, mas como trigger para ações prazerosas e criativas, e estas não se podem continuar a restringir à atuação apenas junto das populações mais novas e independentes.

Perspetiva recentemente desenvolvida pela literatura, Cohen chega mesmo a criar o conceito de creative ageing ${ }^{8}$. Associado ao bem-estar (Cohen, 2006; Flood \& Phillips, 2007; Woodhouse, 2013) e a uma melhor saúde mental (Garcês, Pocinho \& Jesus, 2013), a verdade é que um estilo de vida criativo em fases mais avançadas da vida transforma o indivíduo num sujeito autoempreendedor, descartando o envelhecimento enquanto declínio (Fristrup, 2013). A velhice passa a ser assumida não necessariamente como uma derrota mas como oportunidade; uma fase do desenvolvimento de enormes ganhos.

Estes ganhos em anos de vida produzem alterações na existência humana, presente e o futuro, e exigem novos comportamentos, estilos de vida, expetativas e valores obrigando a um questionamento sobre representações sociais estereotipadas e a ter em conta a explosão de singularidades, no âmbito do direito inclusivo. (Governo de Portugal, 2012: 5)

A própria OMS $(2002 ; 2015)$ alerta para o valor das pessoas idosas enquanto fonte de importantes contribuições para a sociedade. Assume que o novo paradigma encara a aprendizagem como algo que diz respeito a todas as idades, e que o suporte para tais oportunidades deve ser garantido. As pessoas idosas mantêm a sua capacidade para aprender, crescer e tomar decisões, estando com isto implicados múltiplos processos envolvidos na manutenção de um envelhecimento saudável. Culturalmente desvalorizada ou respeitada, a velhice é uma realidade com a qual todos teremos de 
lidar. Através de atividades criativas, pessoas mais velhas podem melhorar o seu sentido de self (Flood \& Phillips, 2007).

Valoriza-se a promoção da autonomia, de estilos de vida saudáveis, de redes sociais e familiares, da participação na sociedade, entre outras dimensões (Antunes \& Pereira, 2014; Sousa, 2014). Acredita-se em se facilitar o acesso a um desenvolvimento mais ativo e criativo, bem como em se potenciar melhorias ao nível da comunicação e relacionamento com os outros (Jacob, 2007; Wakeling, 2013). Mas de facto, e concordando com Lima (2010), a simples participação em atividades de lazer não garante, necessariamente, bem-estar. É essencial promover o desenvolvimento de novos papéis e funções sociais e proporcionar ferramentas para a reconstrução da identidade de cada indivíduo idoso, sendo que este acaba por se tornar um dos principais objetivos aquando da intervenção com pessoas mais velhas, especialmente no caso daquelas já a necessitar do apoio de instituições, frequentemente amotivadas, entristecidas e desunidas da sociedade. $O$ envolvimento num projeto deste género poderá se tornar numa vivência única, diferenciada, num poder de transformação interna imensurável.

A fotografia é fruto da própria natureza (Veja, 2004); testemunho artístico, jornalístico e social, cada vez mais acessível, continua a acompanhar os seres humanos desde há séculos até um tempo provavelmente eterno. Carter único de captação do momento, a fotografia possibilita a transmissão de emoções de uma forma especialmente única. É uma linguagem que assume várias formas, diferentes aplicações e múltiplas interpretações (Bauret, 2000). Permite que entremos em contato com nossos conteúdos mais profundos, abrindo caminhos para a reflexão e para a possível transformação da forma como percecionamos o que nos rodeia (Bulla Júnior, 2005). Pelas razões apresentadas anteriormente e tantas mais, a fotografia assume um potencial de intervenção imenso, nomeadamente, no que toca ao uso da mesma de forma participativa em contexto de investigação-ação, particularmente útil com pessoas idosas.

Um estudo relacionado com o âmbito deste artigo foi o de Lewinson, Robinson-Dooley e Grant (2012), que implementaram um programa de photovoice junto de pessoas idosas que viviam numa residência assistida. Os autores optaram por esta metodologia por considerarem uma forma efetiva de investigar o que os sujeitos consideravam que seria importante, a nível das instalações, para que se sentissem mais «em casa». A partir deste estudo perceberam, por exemplo, que os aspetos estéticos tinham muito menos importância do que o desenvolvimento de atividades com sentindo, bem como a perceção de inclusão social. Para além destes domínios gerais, pelo facto de estarem a trabalhar com as perspetivas dos próprios residentes, detetaram-se pormenores 
funcionais, de enorme importância para os participantes e sobre os quais os mesmos conseguiram propor sugestões.

A entrada num lar comporta sempre a ameaça da identidade e da individualidade do idoso, forçado a enfrentar condições de vida de maior dependência e alterando, inevitavelmente, a sua perceção de bem-estar. Neste enquadramento, as atividades são consideradas de enorme pertinência (Jacob, 2007; Lima, 2004), essenciais na promoção de experiências de resgate da identidade da pessoa institucionalizada (Sousa, 2014), forma privilegiada de promoção da mudança social (Serrano, 1997).

Numa investigação realizada em Portugal com idosos institucionalizados (Esgalhado et al., 2014), por exemplo, percebeu-se que a satisfação com as atividades sociais não estava associada a uma maior perceção de bem-estar psicológico, o que pode evidenciar que as mesmas poderiam não estar a ser percecionadas como desafiadoras, interessantes ou úteis. Parece ser importante que este envolvimento aconteça em atividades continuadas, úteis, que tenham objetivo, enfim, que «valham a pena» (Lima, 2010) e que sejam mais francamente avaliadas e monitorizadas.

E se muitos idosos nunca pegaram numa câmara fotográfica, muitos deles gostariam, provavelmente, de o poder fazer, proporcionando-se experiências novas que, ao mesmo tempo, possibilitam novas formas de comunicar a sua própria realidade. Para além do mais, podemos assumir que se a aquisição de conhecimentos tiver como mediação os afetos, maior será a probabilidade de efetivar a aprendizagem a níveis mais profundos (Featherstone, 1995 citado por Kowalski, 2013). Nasce daqui a ideia do Photovoice com este tipo de grupos: uma oportunidade real e justa de dar voz a pessoas institucionalizadas sobre os cuidados que elas próprias recebem, sobre os aspetos que consideram fundamentais para o seu bem-estar, sobre aquilo que thes é mais fundamental para a sua felicidade. Fazê-lo utilizando metodologias criativas, artísticas até, que se recorrem da imagem como forma de expressar o que pode ser extremamente difícil de definir com palavras, será consonante com todas as indicações anteriormente expressadas.

É urgente deixar de partir do pressuposto de que se sabe o que idosos precisam para a melhoria do seu bem-estar e qualidade de vida. É raro o envolvimento de pessoas idosas enquanto parceiras nos processos de investigação (Blair \& Minkler, 2009). É preciso reinventar a sociedade contemporânea, modificar práticas e discursos (Caballero et al., 2013), dar voz àqueles por quem almejamos intervir, na sua complexidade e idiossincrasias, no seu poder de saber sobre si mesmos. "Falar em humanismo e negar os homens é uma mentira" (Freire, 2005: 94).

A fotografia tirada por alguém pertencente à própria comunidade reflete uma aproximação ao real que não se conseguiria por alguém de fora (Kowalski, 2013). Para 
além do mais, investigações qualitativas têm a potencialidade de contribuir com informações mais ricas acerca de cada população (Silva, 2009), aumentando a probabilidade de se gerarem programas de intervenção mais apropriados e eficazes. Indubitavelmente, a fotografia é uma forma universal e criativa de expressão, possibilitando abordar um largo espetro de conceitos inatingíveis, tais como desigualdade, construção da realidade, poder e conflito, entre outros. A metodologia Photovoice parece encaixar com perfeição como uma das respostas possíveis. 0 objetivo não é resolver problemas, mas sim potenciar capacidades e competências criativas, valorizando a identidade e a vontade de cada um.

Investigações na área do bem-estar têm indicado que o envolvimento em objetivos mais intrínsecos e persistentes associam-se à felicidade (Novo, 2005). Nesta interligação entre sentimentos e emoções, os afetos, lado vivencial e relacional, assumem um caráter particularmente pertinente quando em solidão. Usar o Photovoice como forma de investigar o bem-estar e trabalhar internamente emoções numa comunidade de pessoas institucionalizadas pode até ser, mais que um simples método, derradeira ferramenta de envolvimento ativo, reconstrução de significados e reencontro pessoal.

\section{Notas Finais}

Em Portugal, o Roteiro para a Educação Artística (UNESCO, 2006) propôs-se explorar o papel da Educação Artística na satisfação da necessidade de criatividade e de consciência cultural, valorizando as artes como parte do Ser, em ambientes formais e não formais, defendendo o direito humano à educação e à participação cultural, documento marco no nosso país da evolução da cultura artística enquanto algo para todos. O recurso às Artes como forma de intervenção, seja individualmente ou com grupos, tem vindo a ser cada vez mais utilizado, especialmente pelas características criativas atrás referidas. Em termos investigativos, por sua vez, as pesquisas qualitativas têm requerido o seu valor, em particular, no que toca a metodologias participativas que privilegiam a voz do sujeito de investigação ao invés da perspetiva do próprio investigador, adquirindo os resultados uma maior significância social.

As políticas no domínio do envelhecimento são de uma enorme pertinência para a melhoria do posicionamento social da pessoa idosa e pela efetiva potenciação de uma sociedade justa e coesa (Carvalho, 2014). Na verdade, elas têm feito o seu caminho (Capucha, 2014), permitindo que as pessoas vivam mais tempo, com mais acesso a mais recursos. No entanto, é provavelmente consensual que muito haverá a fazer pela promoção do bem-estar de pessoas idosas.

No nosso país, na legislação ainda permanece uma desadequação estrutural, ética e social (Tomé et al., 2015), tornando-se evidente que a mesma continua a valorizar a 
burocratização como padrão de qualidade. Não basta proporcionar atividades de lazer para garantir uma melhoria do bem-estar da pessoa idosa; como refere Lima (2010), é de enorme importância considerar também a qualidade e o significado que tais atividades assumem para estas pessoas, e que tal varia com a idade, as histórias de vida, as experiências, os interesses, as oportunidades, enfim, com as idiossincrasias de cada um. O conceito de velhice é demasiado generalizado; as suas representações e categorias nem sequer correspondem mais à realidade social da idade (Cardoso et al., 2012).

A investigação-ação participativa com idosos, nomeadamente a que utiliza metodologias colaborativas visuais, está pouco desenvolvida (Blair \& Minkler, 2009). Apesar do recurso às novas tecnologias se mostrar promissor, a investigação continua a escassear em Portugal. É por isso necessário investir em ações pensadas, estruturadas e continuadas, que possam fornecer elementos de informação reais sobre como intervir nesta nova fase da evolução humana, em que a pirâmide demográfica exige uma atuação imediata mas, ao mesmo tempo, digna e respeitadora. É igualmente pertinente perceber que é preciso haver conhecimento das técnicas que se empregam, refletindo-se sobre as mesmas e nunca descurando a formação.

Numa época de cortes orçamentais políticos, é fundamental confirmar a efetividade de programas criativos e o impacto da participação em atividades artísticas por pessoas idosas. As ações de investigação participativa, ao direcionarem para o que é realmente importante para cada comunidade, têm a potencialidade de assumir um importante papel na redistribuição dos fundos e dos investimentos (Wang \& Burris, 1997), tanto ao nível público como privado.

Considero fundamental que os idosos possam estar eles próprios mais implicados nas transformações das suas próprias vidas, enquanto agentes ativos, protagonistas do seu próprio desenvolvimento, principais decisores das suas opções. Um projeto que está a iniciar, e no qual o desenvolvimento deste artigo se insere, procura potencializar que tal aconteça, mas também que as reflexões que advirem promovam realmente a mudança ${ }^{1}$. Para além dos mais, os «problemas sociais» do mundo contemporâneo exigem mais

\footnotetext{
1 O "Photovoice Nunca Pensei" é um projeto de fotografia participativa, cuja ideia passa por entregar máquinas fotográficas a pessoas de determinada comunidade, neste caso, idosas, para que estas possam expressar através da imagem as suas preocupações problemas e emoções. Durante cerca de três meses, os participantes (autonomamente) respondem a desafios e questões com fotografias, trabalhando semanalmente e em grupo os "porquês" das suas escolhas. Nesta primeira edição, foram quatro os residentes do lar da ADSFAN a participarem na iniciativa. Pessoas do concelho de Óbidos ou Caldas que, com mais de 80 anos, pegaram pela primeira vez numa máquina fotográfica. "Nunca Pensei" ficou o nome deste projeto de fotografia participativa com pessoas idosas, escolhido pelos próprios participantes, intitulando assim a primeira exposição: "Nunca Pensei Ser Artista!" Para acompanhar o projeto poderá consultar a página do mesmo em https://www.facebook.com/rosalindachavespsicologia/.
} 
saber científico, por forma a se encontrarem metodologias de ação mais adaptadas e, também, eficazes, reinventadas a cada trabalho (Quivy \& Campenhoudt, 2005).

De futuro, é importante alargar o leque de cenários alternativos para os idosos, de forma a facilitar as escolhas, em que se verifique a adequação da pessoa ao ambiente, tendo em consideração que mesmo no reduzidíssimo leque de alternativas que se colocam actualmente aos idosos, elas são sempre uma construção que se vai realizando ao logo da vida, assumindo claramente o carácter de continuidade, e não de ruptura com a vida passada. (Paúl, 1997: 157)

É de enorme importância continuar a apostar-se num melhor entendimento dos fatores associados à realidade da institucionalização, seu impacto na vida do idoso e continuar a fomentar a implementação de boas práticas neste género de cuidados, para que melhor se promova o bem-estar destas pessoas. É preciso que as medidas tomadas tenham mais em conta as características individuais de cada grupo, em cada comunidade. É extremamente necessário continuar a refletir sobre esta questão, assumir e investigar todas as perdas mas também mais-valias e oportunidades que representam a entrada num lar, compreender idiossincraticamente as dificuldades do processo que é envelhecer e não esquecer como os próprios pré-conceitos dos técnicos influenciam o género de cuidados prestados. Fazer o melhor que conseguimos pela humanidade, é cuidar conscienciosamente de nós mesmos.

Se a terceira idade para muitos representa aprisionamento, para outros, é o seu momento, o que está a ser vivido, que, portanto, deve ser sentido com o mesmo amor e dedicação que os restantes. As metodologias visuais participativas podem-se assumir como vitais neste sentido, verdadeiros instrumentos criativos, colaborativos e de efetiva aplicabilidade. Cabe a todos nós descobrir como ajudar a que este processo seja possível - e provável.

\section{Bibliografia}

Antunes, M. \& Pereira, J. (2014). Animação sociocultural e terceira idade. In A. Fontes, J. Sousa, M. Lopes \& S. Lopes (Eds), Cultura, Participação e Animação Sociocultural em Contextos Iberoamericanos (pp. 135-145). Leiria: RIAP - Rede Iberoamericana de Animação Sociocultural.

Barreto, J. (1998). A Realidade Social dos Idosos em Portugal: O Desafio do Ano 2000. Saber (e) Educar, 3, 17-24.

Barreto, J. (2005). Envelhecimento e Qualidade de Vida: o desafio actual. Sociologia, $X V, 289-302$.

Barros de Oliveira, J. (2010). Psicologia do Envelhecimento e do Idoso, Porto: Livpsic. Barthes, R. (1981). A Câmara Clara. Lisboa: Edições 70. 
Bauret, G. (2000). A Fotografia: história, estilos, tendências, aplicações. Lisboa:

Edições 70.

Blair, T. \& Minkler, M. (2009). Participatory Action Research With Older Adults: Key

Principles in Practice. The Gerontologist, 49 (5), 651-662.

Bulla Júnior, L. (2005). Fotografia e Loucura: um olhar sobre a condição humana na experiência do transtorno mental. Discursos Fotográficos, 1, 213-230.

Caballero, M., Lima, M., Costa, J. \& Galvis, C. (2013). Adultos Idosos como Agentes: O Projeto W2P. Revista E-Psi, 3 (1), 48-68.

Campos, R. (2011). Imagem e tecnologias visuais em pesquisa social: tendências e desafios. Análise Social, XLVI (199), 237-259.

Campos, R. (2013). Introdução à Cultura Visual. Abordagens e Metodologias em Ciências Sociais. Lisboa: Mundos Sociais.

Capucha, L. (2014). Envelhecimento e políticas sociais em tempos de crise.

Sociologia, problemas e práticas, 74, 113-131.

Cardoso, S., Santos, M., Batista, M. \& Clemente, S. (2012). Estado e políticas sociais sobre a velhice em Portugal (1990--2008). Análise Social, 204, xIvii (3. ), 606-630.

Carvalho, R. de (1976). História da Fotografia - ciência para gente nova $n^{\circ} 2$. Coimbra: Atlântida.

Carvalho, M. (2014). Social work and intervention with older people in Portugal: a critical point of view. European Journal of Social Work, 17 (3), 336-352.

Carvalho, M. \& Dias, M. (2011). Adaptação dos Idosos Institucionalizados. Millenium, 40, 161-184.

Catalini, C. \& Minkler, M. (2010). Photovoice: A Review of the Literature in Health and Public Health. Health Education \& Behavior, 37 (3), 424-451.

Cohen, G. (2006). Research on Creativity and Ageing: The Positive Impact of the Arts on Health and Ilness. Generations, XXX (I), 7-15.

Crespo, A. \& Pulido, P. (2014). La Fotografia Participativa en el contexto sócioeducativo com adolescentes. Comunicación y Hombre, 10, 143-156.

Cronin, Ó. (1998). Psychology and Photographic Theory. In J. Posser (Eds.), Imagebased Research - A Sourcebook for Qualitative Researchers (pp. 69 - 83). Londres e Nova lorque: Routledge.

Damásio, A. (2003). Ao Encontro de Espinosa: as emoções sociais e a neurologia do sentir. Lisboa: Europa América.

Dubois, P. (1993). O Ato Fotográfico e Outros Ensaios. Campinas: Papirus.

Esgalhado, G.; Reis, M., Pereira, H. \& Afonso, M. (2014). Bem-estar Psicológico e Suporte Social numa Amostra de Idosos Portugueses Institucionalizados. International Journal of Developmental and Educational Psychology, 2 (1), 401-410. 
Flood, M. \& Phillips, K. (2007). Creativity in older adults: A plethora of possibilities. Issues in Mental Health Nursing, 28, 389-411.

Fonseca, A. (2004). O Envelhecimento - Uma abordagem psicológica. Lisboa:

Universidade Católica Portuguesa.

Formosa, M. (2013). Creativity in Later Life: possibilities for personal empowerment. Fornvårdaren, 34, 78-93.

Fragoso, V. (2012). Emoção, Sentimento e Afeto na senioridade. In V. Fragoso \& M. Chaves [Org.], Educação Emocional para Seniores (pp. 55 - 107). Viseu: Psicosoma. Freire, P. (1979). Educação e Mudança. São Paulo: Paz e Terra.

Freire, P. (2005). Pedagogia do Oprimido. Rio de Janeiro: Paz e Terra.

Fristrup, T. (2013). Craving Creativity in Later Life. Fornvårdaren, 34, 56-77.

Galinha, I. \& Pais-Ribeiro, J. (2005). História e Evolução do Conceito de Bem-Estar Subjectivo. Psicologia, Saúde \& Doenças, 6 (2), 203-214.

Gama, A., Teodoro, A. \& Simões, A. (2014). Participação dos idosos: percursos construídos por finalistas da licenciatura em animação sociocultural. In A. Fontes, J. Sousa, M. Lopes \& S. Lopes [Eds.], Cultura, Participação e Animação Sociocultural em Contextos Iberoamericanos (pp. 146 -159). Leiria: RIAP - Rede Iberoamericaba de Animação Sociocultural.

Garcês, S., Pocinho, M. \& Jesus, S. (2013). Predição da criatividade e saúde mental. Psicologia, Saúde \& Doenças, 14 (2), 272-279.

Governo de Portugal (2012). Ano Europeu do Envelhecimento Ativo e da Solidariedade entre Gerações. Programa de Ação, 2012. Consultado em: http://www.igfse.pt/upload/docs/2012/Programa\%20A\%C3\%A7aoAnoEuropeu201 2.pdf

Griebling, S., Vaughn, L., Howell, B., Ramstetter, C. \& Dole, D. (2013). From Passive to Active Voice: Using Photography as a Catalyst for Social Action. International Journal of Humanities and Social Science, 3 (2), 16-28.

Guedes, J. (2012). Viver num Lar de Idosos: Identidade em Risco ou Identidade Riscada? Lisboa: Coisas de Ler.

Harper, D. (2002). Talking about pictures: a case for photo elicitation. Visual Studies, 17 (1), 13-26.

Harrison, B. (2002). Seeing health and illness worlds - using visual methodologies in a sociology of health and illness: a methodological review. Sociology of Health \& IIIness, 24 (6), 856-872.

Hilário, F. (2007). A Arte: entretenimento, jogo e terapia. In J. Pereira, F. Vieites \& M. Lopes (Coord.), Animação, Artes e Terapias (pp. 53 - 58). Ponte de Lima: Intervenção. 
Instituo Nacional de Estatística [INE] (2011). Censos 2011 - Resultados Provisórios. Lisboa: Instituto Nacional de Estatística.

Instituto Nacional de Estatística [INE] (2014). Projeções de População Residente 20122060. Destaque, 1-18.

Jacob, L. (2007). Animação de Idosos - Actividades. Porto: Ambar.

Jacob, L. (2012). Respostas Sociais para Idosos em Portugal. In F. Pereira (Coord.),

Teoria e Prática de Gerontologia - Um guia para cuidadores de Idosos (pp. 129-147).

Viseu: Psicosoma.

Kowalski, M. (2013). O tempo na fotografia. IV Colóquio Internacional de

Doutorandos/as do CES. Lisboa: CES. Consultado em

http://cabodostrabalhos.ces.uc.pt/n10/documentos/6.1.3_Maria_Pereira_Kowalsk i. pdf

Lamas, M. \& Paúl, C. (2013). O envelhecimento do sistema sensorial: implicações na funcionalidade e qualidade de vida. Actas de Gerontologia, 1 (1), 1-11.

Lewinson, T., Robinson-Dooley, V. \& Grant, K. (2012). Exploring "Home" Through

Resident's Lenses: Assisted Living Facility Residents Identify Homelike Characteristics Using Photovoice. Journal of Gerontological Social Work, 55 (8), 745-756.

Lima, M. (2004). Posso Participar? Actividades de desenvolvimento pessoal para idosos. Porto: Ambar.

Lima, M. (2010). Envelhecimento - Estado da Arte. Coimbra: Imprensa da Universidade de Coimbra.

Machado, W. \& Bandeira, D. (2012). Bem-estar psicológico: definição, avaliação e principais correlatos. Estudos de Psicologia, 29 (4), 587- 595.

Martin, M. (1987). Semiología de la Imagen y Pedagogía: Por una pedagogia de la investigación. Madrid: Narcea.

Meirinho, D. (2012). A Fotografia Participativa como ferramenta de expressão e representação social. Foto-ensaio do Projecto "Olhares em Foco". Cadernos de Arte e Antropologia, 1, 77-82.

Meirinho, D. (2015). Olhares do saber e do fazer: O uso do método Photovoice como instrumento para a literacia visual em contextos de exclusão e vulnerabilidade. In M. J. Brites, A. Jorge \& S. C. Santos [Eds.], Metodologias Participativas: Os media e a educação (pp. 203-212). Covilhã: LabCom Books.

Miguel, I. (2014). Envelhecimento e Desenvolvimento Psicológico: entre mitos e factos. In H. da Luz \& I. Miguel (Coord.), Gerontologia Social - Perspetivas de análise e intervenção (pp. 53-68). Coimbra: Instituto Superior Bissaya Barreto.

Milhano, S. (2012). Motivações e perceções da participação num projeto de valorização do envelhecer através das artes e da música - um estudo exploratório. In 
F. Canastra, G. Santos \& M. Lopes (Org.), Animação Cultural: Descobrindo Caminhos (pp. 67-83). Leiria: ESECS / NIDE / CIID / Instituto Politécnico de Leiria.

Milhano, S. (2014). Práticas musicais e artísticas e a (re)construção de identidades numa comunidade sénior. In A. Fontes, J. Sousa, M. Lopes \& S. Lopes [Eds.], Cultura, Participação e Animação Sociocultural em Contextos Iberoamericanos (pp. 223-233). Leiria: RIAP - Rede Iberoamericaba de Animação Sociocultural.

Moody, H. (2002). Controversy 9: Does Creativity Declines With Age? In H. Moody, Aging: Concepts and controversies (pp. 368-390). Thousand Oaks: Pine Forge. Neto, M., Corte-Real, J. (2013). The Elder institutionalized: depression and social support. Journal of Aging \& Inovation, 2 (3), 26-41.

Novo, R. (2005). Bem-Estar e Psicologia: Conceitos e Propostas de Avaliação. RIDEP, 20 (2), 183-203.

Oliveira, J. (2007). Terapia pela Arte numa abordagem hermenêutica. In J. Pereira, F. Vieites \& M. Lopes [Coord.], Animação, Artes e Terapias (pp. 215-223). Ponte de Lima: Intervenção: Associação para a promoção e divulgação cultural.

Organização Mundial de Saúde [OMS] (2001). Men, ageing and health. Achieving health across the Span. Geneva: World Health Organization.

Organização Mundial de Saúde (2002). Active Ageing: A Policy Framework. Geneva: World Health Organization. Consultado em http://apps.who.int/iris/bitstream/10665/67215/1/WHO_NMH_NPH_02.8.pdf Organização Mundial de Saúde (2015). World Report on Ageing and Health. Geneva: World Health Organization. Consultado em http://www.who.int/kobe_centre/mediacentre/world_report_on_ageing_and_healt h_eng.pdf

Osorio, A. (2008). Animação Sociocultural na Terceira Idade. In J. Pereira, F. Vieites \& M. Lopes (Coord.), A Animação Sociocultural e os Desafios do Séc. XXI (pp. 207-219). Ponte de Lima: Intervenção: Associação para a promoção e divulgação cultural. Ostrower, F. (1993). Criatividade e Processos de Criação, 9a edição. Petrópolis: Vozes.

Pais-Ribeiro, J. (1994). A importância da qualidade de vida para a psicologia da saúde. Análise Psicológica, 2-3 (XII), 179-191.

Pais-Ribeiro, J. (2009). A importância da qualidade de vida para a psicologia da saúde. In J.P. Cruz, S.N. de Jesus, \& C Nunes (Coord.), Bem-Estar e Qualidade de Vida (pp.31-49). Alcochete: Textiverso.

Palibroda, B., Krieg, B., Murdock L. \& Havelock, J. (2009). A Practical Guide to Photovoice: Sharing Pictures, telling stories and changing communities. Winnipeg: 
Prairie Women's Health Centre of Excellence. Consultado em

http://www.pwhce.ca/photovoice/pdf/Photovoice_Manual.pdf

Paúl, C. (1997). Lá para o fim da vida - idosos, família e meio ambiente. Coimbra:

Almedina.

Paúl, C. (2005). Envelhecimento activo e redes de suporte social. Sociologia, Revista da Faculdade de Letras, 15, 275-287.

Pereira, F. (2012). A Ideia de Vida Ativa. In F. Pereira (Coord.), Teoria e Prática de Gerontologia - Um guia para cuidadores de Idosos (pp. 207-214). Viseu: Psicosoma. PhotoVoice.org (s.d). The PhotoVoice Manual: A guide to designing and running participatory photography projects. PhotoVoice.org. Consultado em http://www.photovoice.org/wp-content/uploads/2014/09/PV_Manual.pdf Posser, J. (1998). The Status of Image-based Research. In J. Posser [Eds.], Imagebased Research - A Sourcebook for Qualitative Researchers (pp. 97 - 112). Londres e Nova lorque: Routledge.

Quivy, R. \& Campenhoudt, L. (2005). Manual de Investigação em Ciências Sociais - $4^{a}$ edição. Lisboa: Gradiva.

Rebelo, H. (2007). Psicoterapia na idade adulta avançada. Análise Psicológica, 4 (XXV), 543-557.

Ribeiro, O. (2012). O envelhecimento "ativo" e os constrangimentos da sua definição. Sociologia, Envelhecimento demográfico, 33 - 52.

Roberto, M., Fidalgo, A. \& Buckingham, D. (2014). "Estas memórias que os retratos nos dão" - análise de um programa de inclusão digital aplicado em contexto de lar de terceira idade. Investigar em Educação, I/ (1), 199-218.

Rodrigues, F. (2011). Educação do Olhar. Lisboa: Chiado.

Rogers, C. (1974). Tornar-se Pessoa, $2^{a}$ edição. Lisboa: Moraes.

Romero, M., Hyvönen, P. \& Barberà, E. (2012). Creativity in Collaborative Learning across the Life Span. Creative Education, 3 (4), 422-429.

Runco, M. (2004). Creativity. Annual Review of Psychology, 55, 657-687.

Ryff, C. (1989). Happiness is everything, or is it? Explorations on the meaning of psychological well-being. Journal of Personality and Social Psychology, 57, 1069-1081. Sequeira, C. (2010). Cuidar de Idosos com Dependência Física e Mental. Lisboa: Lidel.

Scharf, A. (1994). Arte y fotografia. Madrid: Alianza.

Serrano, G. (1997). Metodologias de Investigação em Animação Sociocultural. In J. Trilla (Coord.), Animação Sociocultural - Teorias, Programas e Âmbitos (pp. 101-119). Lisboa: Instituto Piaget - Ariel. 
Silva, S. (2009). Qualidade de Vida e Bem-estar Psicológico em Idosos. Dissertação de Mestrado. Universidade Fernando Pessoa, Porto.

Sousa, J. (2014). Superar o luto: as atividades socioculturais na intervenção com as pessoas idosas institucionalizadas. In A. Fontes, J. Sousa, M. Lopes \& S. Lopes (Eds.), Cultura, Participação e Animação Sociocultural em Contextos Iberoamericanos (pp. 169 - 180). Leiria: RIAP - Rede Iberoamericaba de Animação Sociocultural. Souza, S. \& Lopes, A. (2002). Fotografar e Narrar: A produção do conhecimento no contexto da escola. Cadernos de Pesquisa, 116, 61-80.

Tomé, A., Rodrigues, C., Costa, S. \& Marques, S. (2015). Evolução da Legislação para Estruturas Residenciais e a Estigmatização do Envelhecimento em Portugal. Journal of Aging \& Inovation, 4 (2), 11-20.

UNESCO (2006). Roteiro para a Educação Artística: Desenvolver as Capacidades Criativas para o Século XXI. Lisboa: Comissão Nacional da UNESCO.

Vega, C. (2004). El ojo en la mano: La Mirada fotográfica en el siglo XIX. Girona: CCG. Wakeling, K. (2013). Creativity and Subjective WellBeing among Older People: A Literature Review. Londres: Trinity Laban Conservatoire of Music \& Dance. Wallerstein, N. \& Bernstein, E. (1988). Empowerment Education: Freire's Ideas Adapted to Health Education. Health Education Quarterly, 15 (4), 379-394.

Wang, C. (1999). Photovoice: A Participatory Action Research Strategy Applied to Woman's Health. Journal of Women's Health, 8 (2), 185-192.

Wang, C. \& Burris, M. (1997). Photovoice: Concept, Methodology, and Use for Participatory Needs Assessment. Health Education \& Behavior, 24 (7), 369-387. Woodhouse, A. (2013). Exploring the Impact of Participatory Arts on Older People: what the research literature tell us. Fornvårdaren, 34, 35-55.

Rosalinda Chaves licenciou-se em Psicologia Clínica, em 2009, na Universidade da Beira Interior. Estagiou e trabalhou na área do tratamento de dependências entre 2010 e 2014. Nesse ano, passou a integrar a equipa da ADSFAN (Associação de Desenvolvimento Social da Freguesia de A-dos-Negros), uma instituição do concelho de Óbidos dedicada ao apoio à população idosa. Frequentou diversas formações, entre as quais uma Pós-Graduação em Mindfulness e outra em Psicogerontologia. É mestranda em Intervenção e Animação Artísticas, pela Escola Superior Educação e Ciências Sociais do Instituto Politécnico de Leiria.

\rosalinda.chaves@gmail.com 